\title{
Late Onset Cerebrospinal Fluid Leakage Associated With Past Head Injury
}

\author{
-Two Case Reports-
}

\author{
Haruna KAMOCHI, ${ }^{1}$ Gen KUSAKA, ${ }^{1}$ Mami ISHIKAWA, ${ }^{1}$ \\ Sane ISHIKAWA, ${ }^{2}$ and Yuichi TANAKA ${ }^{1}$
}

Departments of ${ }^{1}$ Neurosurgery and ${ }^{2}$ Endocrinology and Metabolism, Saitama Medical Center Jichi Medical University, Saitama, Saitama

\begin{abstract}
Late onset cerebrospinal fluid (CSF) leakage, such as rhinorrhea or otorrhea, is a rare complication of closed head injury. We encountered two cases of delayed CSF leakage more than 10 years after head injury. In both cases, surgical treatments were performed using intradural approaches, and the dural defects were closed with viable pedicled flaps. After surgery, the CSF leakage was completely cured and no remarkable complication was observed in either case. The present two cases of late onset CSF leakage suggest that surgical repair procedures should be performed as soon as the leaks are discovered. A bifrontal intracranial approach is recommended to treat frontal cranial base leakage. Temporal craniotomy is recommended to treat temporal base leakage. All cases should be treated using an intradural approach, and the dural defect is best repaired with viable pedicled flaps.
\end{abstract}

Key words: late onset cerebrospinal fluid leakage, delayed rhinorrhea, delayed otorrhea, pedicled flap, intradural approach

\section{Introduction}

Cerebrospinal fluid (CSF) leakage, such as rhinorrhea or otorrhea, is a known complication which increases the risk of bacterial meningitis after head injury. Late-onset CSF leakage is a rare complication after closed head injury. More than $90 \%$ of cases occur within 3 months after the head injury, ${ }^{5}$ whereas cases that present after several years are quite rare. Late-onset CSF otorrhea is especially rare because most otorrhea stops immediately and naturally. ${ }^{4)}$ Most reports recommend immediate surgical repair for the treatment of delayed CSF leakage, ${ }^{5,8}$ but the optimal surgical approach remains controversial. We describe two cases of delayed CSF leakage treated successfully by surgery.

\section{Case Reports}

Case 1: A 66-year-old man was admitted to our department with high fever, headache, and neck stiffness, and was diagnosed with meningitis. More than 20 years previously, he had suffered a severe head injury at work. Neurosurgical operation with craniotomy was undertaken at another hospital. After the operation, there were no complications and no CSF leakage. However, during the past few years, he had noticed serous fluid leakage from his nose. He was diagnosed with bacterial meningitis with

Received November 10, 2011;

Accepted March 23, 2012
CSF rhinorrhea at our hospital. Antibiotic treatment was started immediately. Preoperative computed tomography demonstrated a frontal base bone fracture at the roof of the posterior ethmoidal sinus (Fig. 1). We decided that surgical repair should be undertaken as soon as possible. Bicoronal skin incision and craniotomy with an intradural approach were employed. Under the microscope, we observed a torn and extended bone fracture extending for-

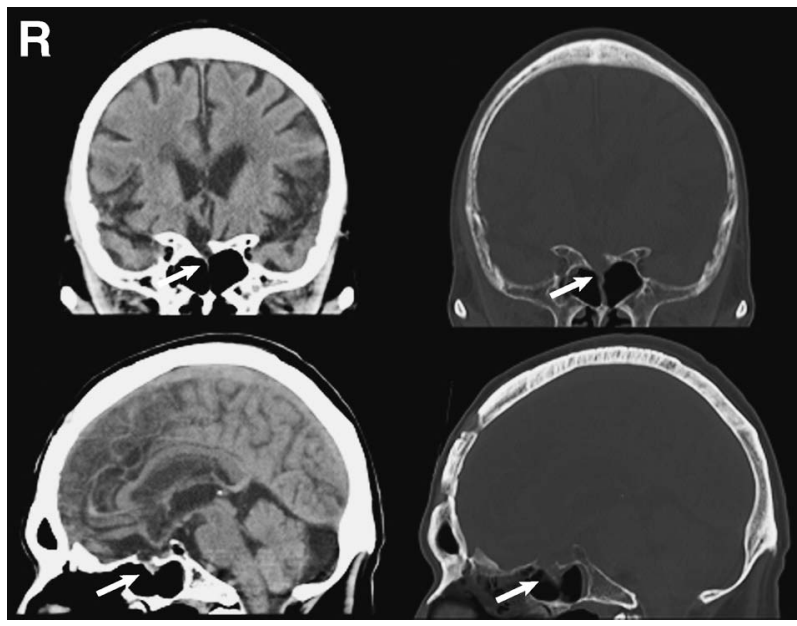

Fig. 1 Case 1. Computed tomography scans showing a bone defect (arrows) in the frontal base bone. 

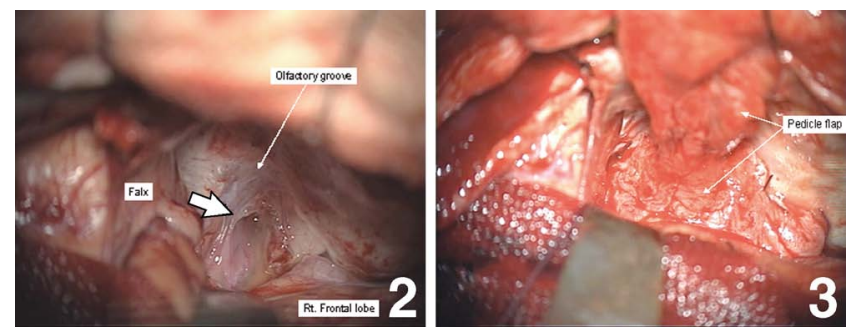

Fig. 2 Case 1. Intraoperative photograph showing retraction of the right frontal lobe to reveal the frontal base. The sphenoidal plane was fractured, with the dura mater torn and extending into the posterior ethmoidal sinus (arrow).

Fig. 3 Case 1. Intraoperative photograph showing the dural defect patched with a vascularized pedicle flap made from galea aponeurotica periosteum.

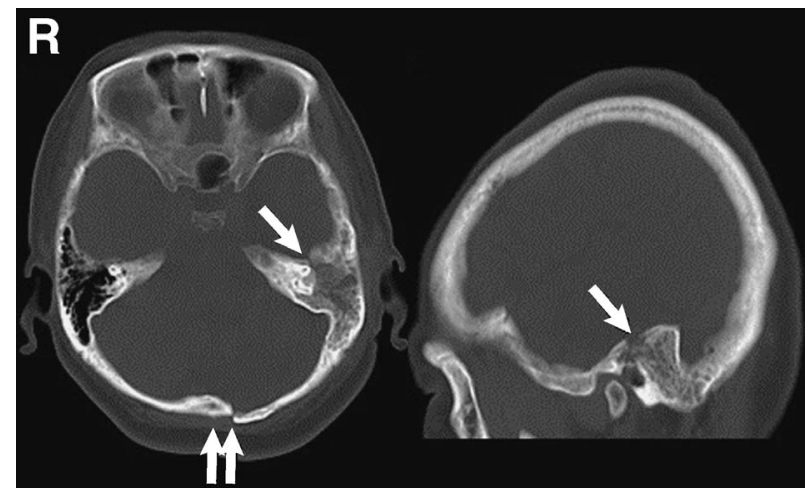

Fig. 4 Case 2. Computed tomography scans showing a left upper pyramidal bone fracture (arrows) and an occipital bone fracture (double arrow).

ward to the posterior ethmoidal sinus (Fig. 2). The area lacking dura mater was covered by fragile connective tissue. The dural defect was repaired with a viable pedicled flap made from galea aponeurotica periosteum, which was prepared during the craniotomy (Fig. 3). There was no evidence of CSF leakage soon after surgery and the patient recovered completely.

Case 2: A 61-year-old woman had suffered a head injury in a traffic accident 10 years before visiting our clinic. After the accident, she was treated surgically by craniotomy at another hospital. There were no complications after the surgery. However, during the past few years, she had noticed serous fluid leakage from her left ear and nose without meningitis. A few days before admission to our hospital, she was diagnosed with CSF leakage by an otolaryngologist at another hospital. CSF leakage from a fracture at the upper pyramidal bone was suspected based on radiographic examination (Fig. 4). We decided on surgical treatment for repairing the CSF otorrhea. A left middle fossa approach with a left temporal craniotomy was used. The pyramidal bone was fractured with the dural tear, which was covered with fragile connective tissue (Fig. 5). The dural defect was patched with a viable pedicled (vascularized) temporoparietal fascial flap (Fig. 6).
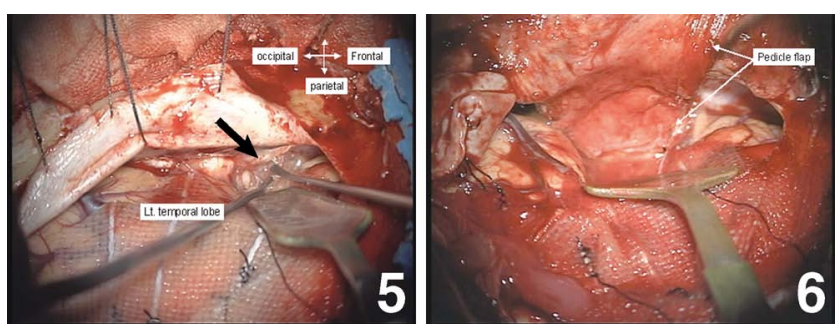

Fig. 5 Case 2. Intraoperative photograph showing pulling of the left temporal lobe to reveal the temporal base. The pyramidal bone was fractured with the torn dura mater. The dural defect was replaced by connective tissue (arrow).

Fig. 6 Case 2. Intraoperative photograph showing the dural defect patched with a vascularized pedicled temporoparietal fascial flap.

After the operation, the CSF otorrhea was completely cured without any complications.

\section{Discussion}

Leakage of CSF occurs in $2 \%$ of all head injuries and $12-30 \%$ of all skull base fractures. ${ }^{3)}$ The frequency of different types of CSF leakage, such as rhinorrhea or otorrhea, was not defined in previous reports. A total of 27 cases of CSF leakage occurred among 1036 cases of closed head injury. ${ }^{1)}$ In this report, $85 \%$ of the 27 cases were CSF rhinorrhea, and $11 \%$ were CSF otorrhea. Furthermore, 51 patients had CSF leakage that occurred 24 hours or more after injury, of which $43 \%$ were rhinorrhea and $33 \%$ were otorrhea. ${ }^{3)} \mathrm{CSF}$ leakage usually occurs within 48 hours after injury and only $5 \%$ of cases show delayed onset of CSF rhinorrhea, which occurs more than 3 months after head injury. ${ }^{5)}$ Thus, CSF leakage appearing more than 10 years after closed head trauma is quite rare. Many reports have shown that acute onset traumatic CSF leakage occurs immediately after bone fracture with dural tears, or after remission of the acute inflammation several days later. ${ }^{5}$ )

The generally accepted explanation for delayed leakage is that the dural defect becomes plugged with brain tissue, as occurred in the present case, or granulation tissue, or that sinus mucosa seals off the CSF leakage but does not provide a barrier against the spread of infection. This interposed tissue then prevents natural dural repair, so a subsequent, often inconsequential, event then disrupts the temporary seal resulting in rhinorrhea. The trigger of late onset CSF leakage is considered to be meningitis, movement, or strong sneezing. ${ }^{11,13,15)}$

Only 13 reported cases of CSF leakage have appeared more than 10 years after closed head injury, including our two cases. A summary of these 13 cases is shown in Table 1. The mean interval between the trauma and the occurrence of leakage was 19.9 years, with a range of 5 to 35 years. Ten of the 13 cases were complicated with meningitis. At the time of the head injury, nine cases received conservative treatment. However, only our two cases underwent surgery to treat the head injury. Only two cases of late onset CSF otorrhea have been reported. ${ }^{4}$ ) This sug- 


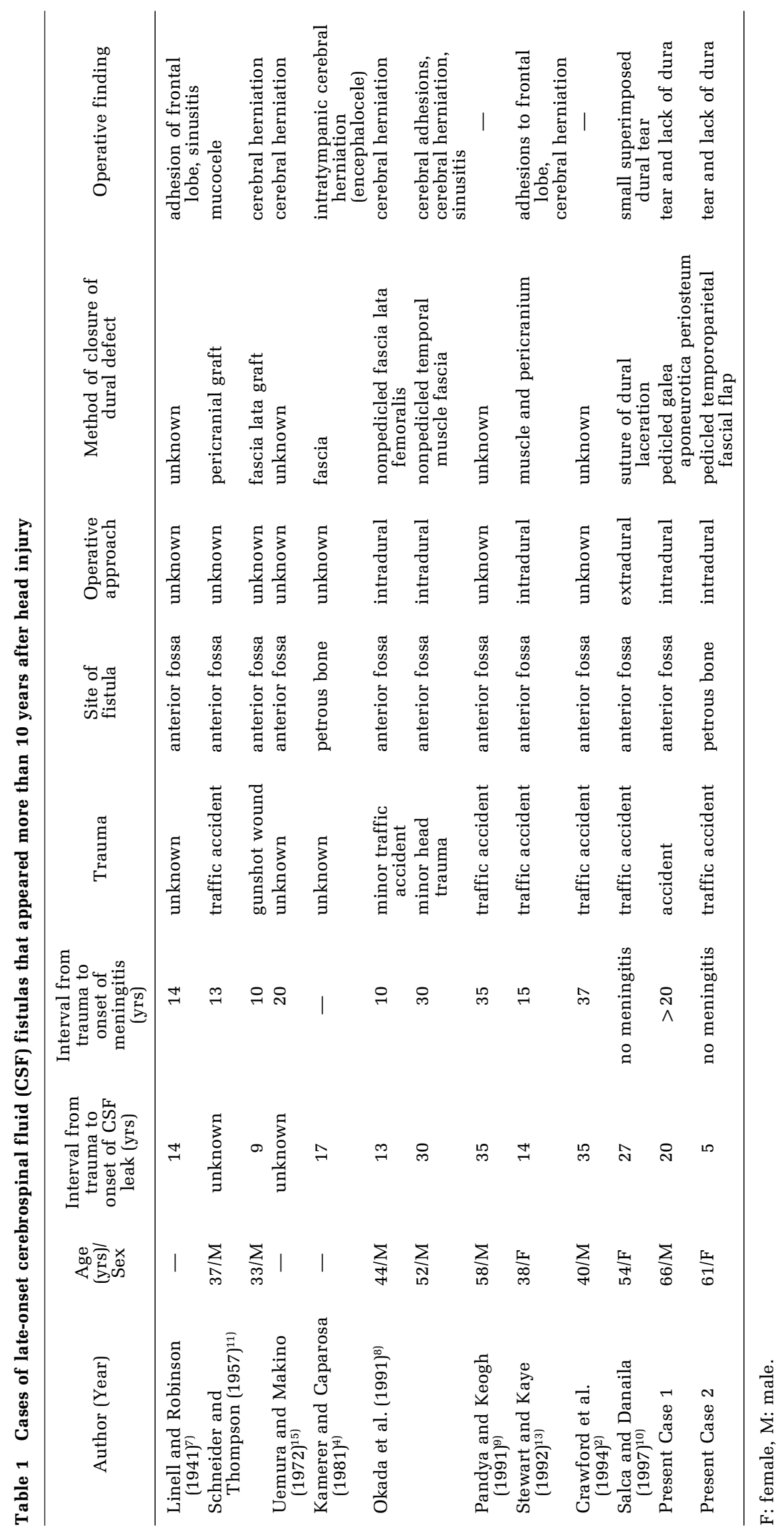


gests that spontaneous closure occurs in the majority of patients with traumatic otorrhea, in contrast to rhinorrhea.

To repair the dural defect, an intradural approach was used in five cases and an extradural approach in one case. Nonpedicled fascia was used in many cases to repair the dural defect. Late onset CSF leakage should be treated by surgical repair as soon as possible if the leakage does not stop after conservative treatment for several weeks and meningitis cannot be adequately managed. ${ }^{6)}$ To repair CSF leaks, an intracranial and/or extracranial approach can be chosen, particularly for CSF fistulae resulting from circumscribed fractures of the medial portion of the anterior cranial base, which can be approached via an extracranial rhinosurgical route with good results. Conversely, large cranial base fractures necessitate surgical treatment via a bifrontal intracranial approach, because they are almost always associated with extensive dural tears and cerebral injury. ${ }^{12)}$

The dural defect can be closed with pericranium, fascia lata, or temporalis fascia and fibrin glue as a sealant. Viable pedicled flaps, such as the epicranium, as used in our series, have great advantages over free grafts. Pedicled flaps are resistant to infection and are integrated more rapidly than free flaps into the recipient site, providing immediate watertight closure, as has been well documented. ${ }^{12,14)}$ We propose that bilateral craniotomy is better, even if radiological studies show unilateral dural defects, because dural tears on the contralateral side are not rare, and both olfactory bulbs may be injured. ${ }^{11)}$ Therefore, in our cases, we used an intradural approach and repaired the dural defect with viable pedicled flaps, such as galea aponeurotica periosteum or temporoparietal fascial flap.

The present two cases of late onset CSF leakage suggest that surgical repair procedures should be performed as soon as the leaks are discovered. A bifrontal intracranial approach is recommended to treat frontal cranial base leakage. Temporal craniotomy is recommended to approach temporal base leakage. All cases should be treated using an intradural approach, and the dural defect is best repaired with viable pedicled flaps.

\section{Conflicts of Interest Disclosure}

The authors have no personal financial or institutional interest in any of the drugs, materials, or devices in the article. All authors who are members of The Japan Neurosurgical Society (JNS) have registered online Self-reported COI Disclosure Statement Forms through the website for
JNS members.

\section{References}

1) Bernal-Sprekelsen M, Bleda-Vázquez C, Carrau RL: Ascending meningitis secondary to traumatic cerebrospinal fluid leaks. Am J Rhinol 14: 257-259, 2000

2) Crawford C, Kennedy N, Weir WR: Cerebrospinal fluid rhinorrhoea and Haemophilus influenzae meningitis 37 years after a head injury. J Infect 28: 93-97, 1994

3) Friedman JA, Ebersold MJ, Quast LM: Post-traumatic cerebrospinal fluid leakage. World J Surg 25: 1062-1066, 2001

4) Kamerer DB, Caparosa RJ: Temporal bone encephalocelediagnosis and treatment. Laryngoscope 92: 878-882, 1981

5) Lewin W: Cerebrospinal fluid rhinorrhea in closed head injuries. Br J Surg 42: 1-18, 1954

6) Lewin W: Cerebrospinal fluid rhinorrhea in nonmissile head injuries. Clin Neurosurg 12: 237-252, 1964

7) Linell EA, Robinson WL: Head injuries and meningitis. J Neurol Neurosurg Psychiatry 4: 23-31, 1941

8) Okada J, Tsuda T, Takasugi S, Nishida K, Toth Z, Matsumoto K: Unusually late onset of cerebrospinal fluid rhinorrhea after head trauma. Surg Neurol 35: 213-217, 1991

9) Pendya PM, Keogh AJ: Traumatic cerebrospinal fluid rhinorrhoea: a timely reminder. Injury 22: 492, 1991

10) Salca HC, Danaila MD: Onset of uncomplicated cerebrospinal fluid fistula 27 years after head injury: case report. Surg Neurol 47: 132-133, 1997

11) Schneider RC, Thompson JM: Chronic and delayed traumatic cerebrospinal rhinorrhea as a source of recurrent attacks of meningitis. Ann Surg 145: 517-529, 1957

12) Scholsem M, Scholtes F, Collignon F, Robe P, Dubuisson A, Kaschten B, Lenelle J, Martin D: Surgical management of anterior cranial base fractures with cerebrospinal fluid fistulae: a single-institution experience. Neurosurgery 62: 463-471, 2008

13) Stewart BT, Kaye AH: Delayed cerebrospinal fluid rhinorrhoea: a case report. Aust N Z J Surg 62: 818-820, 1992

14) Taha M, Carroll T, McMahon J: Vascularized temporoparietal fascial flap for the treatment of a traumatic cerebrospinal fluid fistula in the middle cranial fossa. $J$ Neurosurg 111: 393-395, 2009

15) Uemura $K$, Makino $H$ : [Operative indication and operative method of frontal base skull fracture. Lewin's intradural patch]. Shujutsu 26: 733-742, 1972 (Japanese)

Address reprint requests to: Haruna Kamochi, MD, Department of Neurosurgery, Saitama Medical Center Jichi Medical University, 1-847 Amanuma-cho, Oomiya-ku, Saitama 330-8503, Japan.

e-mail:kamochi@jichi.ac.jp 